\title{
ANALISIS NILAI TAMBAH AGROINDUSTRI KERIPIK BELEDAG DI DESA CITEUREUP KECAMATAN KAWALI KABUPATEN CIAMIS
}

\author{
VALUE ADDED ANALYSIS OF AGROINDUSTRY OF BELEDAG CHIPS IN \\ CITEREUP VILLAGE, KAWALI SUBDISTRICT CIAMIS DISTRICT.
}

\author{
DETI MARYAM ${ }^{1 *}$, IWAN SETIAWAN ${ }^{2}$,AGUS YUNIAWAN ISYANTO ${ }^{1}$ \\ ${ }^{1}$ Fakultas Pertanian, Universitas Galuh \\ ${ }^{2}$ Fakultas Pertanian, Universitas Padjadjaran \\ *E-mail: detimaryam97@gmail.com
}

\begin{abstract}
ABSTRAK
Agroindustri merupakan adalah kegiatan pengolahan suatu produk pertanian dari bahan mentah menjadi bahan jadi atau setengah jadi sehingga menjadi produk yang mempunyai nilai ekonomi yang tinggi. perubahan suatu nilai suatu komoditas karena adanya perlakuan dalam suatu produksi disebeut nilai tambah. .Penelitian ini bertujuan untuk: (1) Mengetahui biaya, penerimaan dan pendapatan agroindustri keripik beledag, dan (2) Menganalisis nilai tambah agroindustri keripik beledag. Penelitian dilaksanakan dengan menggunakan studi kasus pada agroindustry keripik beledag di Desa Citereup Kecamatan Kawali Kabupaten Ciamis. Nilai tambah dianalisis dengan menggunakan metode Hayami. Hasil penelitian menunjukan: (1) biaya total yang dikeluarkan sebesar Rp 54.003.307, penerimaan yang dipeoleh sebesar $\operatorname{Rp} 60.200 .000$, dan pendapatan $\operatorname{Rp} 6.196 .693$, dan (2) Nilai tambah yang diterima sebesar Rp 13.750/kg bahan baku.
\end{abstract}

Kata kunci : Keripik Beledag, Pendapatan, Nilai Tambah, Metode Hayami

\section{ABSTRACT}

Agro-industry is the activity of processing an agricultural product from raw materials into finished or semi-finished materials so that it becomes a product that has high economic value. changes in the value of a commodity due to treatment in a production is called added value. This research aims to: (1) determine the cost, revenue and income of the beledag chips agro-industry, and (2) analyze the added value of the velvet chips agro-industry. The research was conducted using a case study on the beledag chips agroindustry in Citereup Village, Kawali District, Ciamis Regency. The added value was analyzed using the Hayami method. The results showed: (1) the total cost incurred was Rp. 54,003,307, the revenue obtained was $R p$. 60,200,000, and income was $R p .6,196,693$, and (2) the added value received was $R p .13,750 / \mathrm{kg}$ of raw materials.

Keywords: Beledag Chips, Income, Value Added, Hayami Method

\section{PENDAHULUAN}

Agroindustri merupakan suatu kegiatan yang mengolah bahan yang dihasilkan dari usaha pertanian dalam arti luas baik tanaman pangan, non pangan, peternakan maupun perikanan.
Agroindustri adalah proses industrialisasi pada komoditas pertanian dalam rangka meningkaatkan nilai tambah dan daya saingan hasil produk pertanian. Agroindustri adalah solusi yang paling penting untuk penghubung anatara keinginan konsumen dan karakteristik 
produk pertanian yang variatif dan tidak bisa disimpan. (Kurniasari dkk, 2015).

Nilai tambah merupakan penambahan suatu nilai komoditi yang terjadi karena adannya proses pengolahan, pengangkutan dan penyimpanan dalam suatu proses produksi. Konsep dari nilai tambah adalah suatu perubahan nilai suatu komoditas pertanian yang terjadi adanya perlakuan terhadap suatu input pada suatu proses produksi. Nilai tambah secara kuantitatif adalah nilai tambah dari meningkatnya kesempatan kerja, pengetahuan dan keterampilan SDM (Marimin dan Maghfiroh, 2010). Agroindustri Beledag Jagara merupakan industri pengolahan opak menjadi keripik beledag. Opak merupakan olahan yang berbaahan dasar ubi kayu yang diolah terlebih dahulu. Industri rumah tangga Beledag Jagara adalah industri yang cukup besar dan berbeda dari industri pengolahan keripik beledag lainnya, karena industri rumah tangga Beledag Jagara memiliki berbagai varian rasa, yaitu rasa original, keju, cabe ijo, cabe merah, balado, dan rumput laut. agroindustri Beledag Jagara memiliki wilayah pemasaran yang cukup luas, yakni dari Ciamis sampai ke Bali. ubi kayu diolah menjadi keripik beledag diharapkan dapat meningkatkan nilai tambah dari ubi kayu dan mempunyai harga jual yang tinggi. Nilai tambah ubi kayu menjadi keripik beledag dapat meningkatkan pertumbuhan ekonomi dan meningkatkan kesejehahteraan petani dan pelaku usaha.dari uraian diatas makan penelitian ini bertujuan: 1. Mengetahui biaya, penerimaan dan pendapatan pada agroindustri Beledag Jagara di Desa Citeureup Kecamatan Kawali Kabupaten Ciamis 2. Menganalisis nilai tambah pada agroindustri Beledag Jagara di Desa Citeureup Kecamatan Kawali Kabupaten Ciamis.

\section{METODE PENELITIAN}

Jenis penelitian

Jenis penelitian yang digunakan adalah metode studi kasus pada agroindustri beledag jagara di Desa Citereup Kecamatan Kawali Kabupaten Ciamis. Menurut Arikunto (2013), penelitian studi kasus adalah suatu penelitian yang dilakukan secara intensif, terinci dan mendalam terhadap suatu organisasi, lembaga atau gejala tertentu yang ditinjau wilayah penelitian meliputi daerah atau subjek yang sangat sempit dengan sifat penelitian kasus yang lebih mendalam.

\section{Teknik Pengumpulan Data}

Data yang digunakan pada penelitian ini adalah data primer dan data 
sekunder, data primer diperoleh dari wawancara langsung dengan menggunakan kuesioner dan pengamatan langsung, sedangkan data sekunder diperoleh dari studi literatur, jurnal ilmiah, penelitian terdahulu dan lembaga terkait dengan penelitian.

\section{Teknik Penarikan Sampel}

Teknik penarikan sampel yang digunakan pada penelitian ini adalah metode purpossive sampling. purposive sampling adalah teknik pengambilan sampel sumber data dengan pertimbangan tertentu. (Sugiyono (2016),

\section{ANALISIS DATA}

Data yang digunakan pada penelitian ini adalah anlisis biaya, penerimaan dan pendapatan dan analisis nilai tambah menggunakam metode Tabel Hayami.

Analisis biaya adalah besarnya biaya yang digunakan dalam mengolah ubi kayu menjadi keripik beledag dapat diketahui dengan menggunakan analisis biaya dengan rumus sebagai berikut:

$\mathrm{TC}=\mathrm{FC}+\mathrm{VC}$

Keterangan:

$$
\begin{aligned}
& \mathrm{TC}=\text { Biaya total } \\
& \mathrm{FC}=\text { Biaya tetap } \\
& \mathrm{VC}=\text { Biaya variable }
\end{aligned}
$$

Penerimaan adalah perkalian antara produksi yang dihasilkan dengan harga jual dengan persamaan sebagai berikut:

$$
\mathrm{TR}=\mathrm{Q} \times \mathrm{P}
$$

Dimana:

$\mathrm{TR}=$ Penerimaan total (total revenue)

$\mathrm{Q}=$ jumlah produk yang dihasilkan (quantity)

$\mathrm{P} \quad=$ Harga (price)

Besarnya pendapatan atau keuntungan yang diperoleh dari pengolahan ubi kayu menjadi keripik beledag dapat diketahui dengan menggunakan rumus: Pendapatan

$$
(\pi)=\mathrm{TR}-\mathrm{TC}
$$

Keterangan:

$\pi \quad=$ Keuntungan

$$
\begin{array}{ll}
\mathrm{TR} & =\text { Total penerimaan } \\
\mathrm{TC} & =\text { Total biaya }
\end{array}
$$

Nilai tambah pada agroindustry Beledag Jagara dianalisis dengan menggunakan metode Hayami sebagaimana terlihat pada Tabel 1 . 
Tabel 1. Perhitungan Nilai Tambah Metode Hayami

\begin{tabular}{|c|c|}
\hline Variabel & Nilai \\
\hline \multicolumn{2}{|l|}{ I.Input, Output, dan Harga } \\
\hline - Output $(\mathrm{Kg})$ & A \\
\hline - $\quad$ Bahan Baku (Kg) & $\mathrm{B}$ \\
\hline - Tenaga Kerja (HOK) & $\mathrm{C}$ \\
\hline - Faktor Konversi & $\mathrm{D}=\mathrm{A} / \mathrm{B}$ \\
\hline - Koefisien Tenaga Kerja (HOK) & $\mathrm{E}=\mathrm{C} / \mathrm{B}$ \\
\hline - $\quad$ Harga Output $(\mathrm{Rp} / \mathrm{Kg})$ & $\mathrm{F}$ \\
\hline - Upah Rata-Rata Tenaga Kerja (Rp/HOK) & $\mathrm{G}$ \\
\hline \multicolumn{2}{|l|}{ II.Pendapatan dan Keuntungan $(\mathrm{Rp} / \mathrm{Kg})$} \\
\hline - Harga Bahan Baku (Rp/Kg) & $\mathrm{H}$ \\
\hline - Sumbangan Input Lain $(\mathrm{Rp} / \mathrm{Kg})$ & I \\
\hline - $\quad$ Nilai Output $(\mathrm{Rp} / \mathrm{Kg})$ & $\mathrm{J}=\mathrm{D} \times \mathrm{F}$ \\
\hline - Nilai Tambah $(\mathrm{Rp} / \mathrm{Kg})$ & $\mathrm{K}=\mathrm{J}-\mathrm{I}-\mathrm{H}$ \\
\hline - $\quad$ Rasio Nilai Tambah (\%) & $\mathrm{L}=(\mathrm{K} / \mathrm{J}) \times 100 \%$ \\
\hline - Imbalan Tenaga Kerja (Rp/Kg) & $M=E \times G$ \\
\hline - Bagian Tenaga Kerja (\%) & $\mathrm{N}=(\mathrm{M} / \mathrm{K}) \times 100 \%$ \\
\hline - Keuntungan $(\mathrm{Rp} / \mathrm{Kg})$ & $\mathrm{O}=\mathrm{K}-\mathrm{M}$ \\
\hline - Tingkat Keuntungan (\%) & $\mathrm{P}=(\mathrm{O} / \mathrm{K}) \times 100 \%$ \\
\hline \multicolumn{2}{|l|}{ III. Balas Jasa Untuk Faktor Produksi } \\
\hline $\operatorname{Margin}(\mathrm{Rp} / \mathrm{Kg})$ & $\mathrm{Q}=\mathrm{J}-\mathrm{H}$ \\
\hline - Keuntungan $(\%)$ & $\mathrm{R}=\mathrm{O} / \mathrm{Q} \times 100 \%$ \\
\hline - $\quad$ Tenaga Kerja $(\%)$ & $\mathrm{S}=\mathrm{M} / \mathrm{Q} \times 100 \%$ \\
\hline - $\quad$ Input Lain (\%) & $\mathrm{T}=\mathrm{I} / \mathrm{Q} \times 100 \%$ \\
\hline
\end{tabular}

Sumber: Hayami, 1987

HASIL DAN PEMBAHASAN

\section{Karakteristik Responden}

Agroindustri Beledag Jagara adalah industri makanana ringan yang berdiri pada tanggal 3 Maret 2016, beralamat di Dusun Sindangwangi Hilir RT/RW 31/08 Desa Citereup Kecamatan Kawali, Kabupaten Ciamis.
Agroindustri Beledag Jagara didirikan oleh Ai Iip Apipah dan ibu Empat Fatimah. Modal awal pendirian agroindustri Beledag Jagra berupa baku yang ada di rumah, yaitu ubi kayu. Bahan baku yang digunakan pada agroindustri beledag jagara berasal dari para petani yang mengolah ubi kayu menjadi opak di sekitar agroindustri beledag jagara. 


\section{Analisis Biaya, Penerimaan Dan Pendapatan}

Tabel 2. Analisis Biaya, Penerimaan Dan Pendapatan

\begin{tabular}{llrr}
\hline No & \multicolumn{1}{c}{ Jenis Biaya } & Jumlah (Rp) & Persentase (\%) \\
\hline 1. & Biaya tetap & & \\
& a. Pajak & 17.967 & 0,03 \\
& b. Penyusutan alat & 256.667 & 0,48 \\
& c. Bunga modal tetap & 1.373 & 0,00 \\
& Biaya tetap total & $\mathbf{2 7 6 . 0 0 7}$ & $\mathbf{0 , 5 1}$ \\
\hline 2. & Biaya variabel & 30.000 .000 & 55,55 \\
& a. Bahan baku utama & 9.360 .000 & 17,33 \\
& b. Bahan baku penolong & 13.800 .000 & 25,55 \\
& c. Upah tenaga kerja & 300.000 & 0,56 \\
& d. Biaya lainnya & 267.300 & 0,49 \\
& e. Bunga modal variabel & $\mathbf{5 3 . 7 2 7 . 3 0 0}$ & $\mathbf{9 9 , 4 9}$ \\
& Biaya variabel total & $\mathbf{5 4 . 0 0 3 . 3 0 7}$ & $\mathbf{1 0 0 , 0 0}$ \\
\hline 3. & Biaya total & $\mathbf{6 0 . 2 0 0 . 0 0 0}$ & \\
\hline 4. & Penerimaan & $\mathbf{6 . 1 9 6 . 6 9 3}$ & \\
\hline $\mathbf{5}$ & Pendapatan &
\end{tabular}

Sumber: Data Primer, 2020

Tabel 2 menunjukan biaya total yang digunakan pada agoindustri keripik beledag biaya total diperoleh dari penjumlahan biaya tetap dan biaya variabel, biaya tetap adalah biaya yang penggunaannya tidak habis dalam satu kali produksi sedangkan biaya variabel adalah biaya yang habis pada satu kali produksi.biaya total yang diperoleh pada agroindustri keripik beledag adalah sebesar Rp. 54.003.307 dalam satu bulan produksi. Yang diperoleh dari biaya tetap sebesar Rp. 276.007 dan biaya variabel sebesar Rp. 53.727.300 untuk biaya biaya terbesar adalah biaya bahan baku sebesar $\mathrm{Rp}$. 30.000 .000 .
Penerimaan adalah perkalian antara hasil produksi dikalikan dengan harga jual, hasil produksi yang di hasilkan pada agroindustri keripik beledag adalah sebesar $1.400 \mathrm{~kg}$ dan harga jual keripik beledag adalah sebesar Rp. 43.000/kg dengan begitu penerimaan yang diperoleh pada agroindustri keripik beledag adalah sebesar Rp. 60.200.000 dalam satu bulan produksi.

Pendapatan adalah menurut padangaran (2012) merupakan penerimaan yang dikurangi dengan biaya-biaya yang dikeluarkan. Pendapatan pada agroindustri keripik beledag adalah sebesar Rp. 6.196.693 pendapatan diperoleh dari pengurangan penerimaan sebesar Rp. 
60.200 .000 dan total biaya sebesar Rp. 54.003 .307

\section{Analisis Nilai Tambah}

selisih antara komoditas yang mendapat perlakuan pada tahap tertentu dengan nilai korbanan yang digunakan selama proses berlangsung

Hayami et. al. (1987) juga

menyatakan bahwa nilai tambah adalah

\begin{tabular}{lr}
\hline Variabel & Nilai \\
\hline I.Input, Output, dan Harga & 1.400 \\
\hline - $\quad$ Output (Kg) & 1.500 \\
- $\quad$ Bahan Baku (Kg) & 12 \\
- $\quad$ Tenaga Kerja (HOK) & 0.93 \\
- $\quad$ Faktor Konversi & 0.008 \\
- Koefisien Tenaga Kerja (HOK) & 43.000 \\
- Harga Output(Rp/Kg) & 38.333 \\
\hline II.Pendapatan dan Keuntungan (Rp/Kg) & \\
\hline - $\quad$ Harga Bahan Baku (Rp/Kg) & 20.000 \\
- $\quad$ Sumbangan Input Lain(Rp/Kg) & 6.240 \\
- Nilai Output(Rp/Kg) & 39.990 \\
- Nilai Tambah(Rp/Kg) & 13.750 \\
- Rasio Nilai Tambah(\%) & 34 \\
- Imbalan Tenaga Kerja(Rp/Kg) & 306.663 \\
- Bagian Tenaga Kerja (\%) & 2 \\
- Keuntungan (Rp/Kg) & 13.443 \\
- Tingkat Keuntungan(\%) & 97 \\
\hline III. Balas Jasa Untuk Faktor Produksi & 19.990 \\
\hline Margin(Rp/Kg) & 67 \\
- Keuntungan(\%) & 1 \\
- Tenaga Kerja(\%) & 31 \\
\hline
\end{tabular}

Sumber: Data Primer, 2020

Berdasarkan Tabel 3 di atas dapat dilihat bahwa nilai output yang dihasilkan adalah sebesar $1.400 \mathrm{~kg}$ keripik beledag dengan bahan baku sebanyak $1.500 \mathrm{~kg}$. Faktor koversi adalah hasil bagi antara hasil produksi dan output dengan jumlah bahan baku dibagi input yang digunakan, maka besarnya faktor konversi pada agroindustri Beledag Jagara adalah 0,98 yang berarti $1 \mathrm{~kg}$ bahan baku dapat dihasilkan 0.98 keripik beledag.

Nilai tambah yang diperoleh dari keripik beledag sebesar Rp 13.750 yang diperoleh dari pengurangan nilai output dengan biaya input lain dan biaya bahan baku. Sedangkan rasio nilai tambah keripik 
beledag adalah 34\%. Imbalan tenaga kerja pada agroindustri Beledag Jagara didapat dari perkalian koefesien tenaga kerja dengan nilai 12 dengan upah rata-rata tenaga kerja sebesar Rp 30.000/ HOK sehingga didapat $\mathrm{Rp} 306,663 / \mathrm{kg}$ dan bagian tenaga kerja terhadap nilai tambah adalah 2\% Besarnya keuntungan rata-rata yang diperoleh industri rumah tangga Beledag Jagara sebesar Rp 13.443/kg dengan tingkat keuntngan $97 \%$ dari nilai produk. Keuntungan yang dihasilkan merupakan keuntungan total yang diperoleh dari setiap pengolahan keripik beledag.

Hasil analisis nilai tambah menunjukan hasil marjin dari bahan baku keripik beledag yang didistribusikan pada imbalan tenaga kerja, sumbangan input lain dan keuntungan pengusaha. Marjin ini merupakan selisih dari nilai produk dengan harga bahan baku per kilogram dimana setiap pengolahan $1 \mathrm{~kg}$ opak menjadi keripik beledag diperoleh marjin $\mathrm{Rp}$ 19.990/kg yang didistribusikan untuk masing-masing pendapatan tenaga kerja yaitu $1 \%$ sumbangan input lain sebesar $31 \%$ dan keuntungan $67 \%$

Menurut Suryana (1990), kriteria pengujian untuk analisis nilai tambah, antara lain:
Jika rasio nilai tambah > 50\% maka nilai tambah tergolong tinggi

Jika rasio nilai tambah $<50 \%$ maka nilai tambah tergolong rendah.

Nilai tambah pengolahan ubi kayu menjadi keripik beledag adalah sebesar Rp. $13.750 / \mathrm{kg}$ dan rasio nilai tambahnya adalah sebesar $34 \%$. Hal ini berarti bahwa nilai tambah usaha pengolahan ubi kayu menjadi keripik beledag adalah rendah, karena rasio yamg diperoleh sebesar $34 \%$ atau rasio nilai tambah $<50 \%$.

\section{KESIMPULAN DAN SARAN}

\section{Kesimpulan}

Berdasarkan hasil penelitian pada industri rumah tangga Beledag Jagara dapat disimpulkan sebagai berikut:

1. Biaya yang dikeluarkan pada agroindustri Beledag Jagara dalam satu bulan produksi sebesar Rp 54.003.307, penerimaan $\mathrm{Rp}$ 60.200.000, dan pendapatan Rp 6.196.693.

2. Nilai tambah pada agroindustri Beledag Jagara sebesar Rp 13.750/kg.

\section{Saran}

Berdasarkan kesimpulan penelitian, maka diajukan saran sebagai berikut: Penggunaan bahan baku utama merupakan 
biaya terbesar pada agroindustri Beledag Jagara sehingga perlu dicari alternatif bahan baku utama yang harga belinya lebih rendah dalam upaya menurunkan biaya bahan baku utama tersebut

\section{DAFTAR PUSTAKA}

Arikunto, S. 2013. Prosedur Penelitian Suatu Pendekatan Praktik. Jakarta: Rhineka Cipta.

Hayami Y, Kawagoe T, Morooka Y, Siregar M. 1987.Agricultural Marketing and Processing in Upland Java. A Perspective from a Sunda Village. Bogor: The CPGRT Centre.
Kurniasari, E., Kusnandar., F. Widadie. 2014. Analisis Nilai Tambah Manisan Carica di Kabupaten Wonosobo. Skripsi. Fakultas Pertanian, Universitas Sebelas Maret.Surakarta.

Marimin dan Maghfiroh, Nurul. 2010. Aplikasi Teknik Pengambilan Keputusan dalam Manajemen Rantai Pasok. Bandung : IPB Press.

Padangaran, A.M., 2013. Analisis Kuantitatif. Pembiayaan Perusahaan Pertanian. Penerbit IPB Press

Sugiyono. 2016. Metode Penelitian Kuantitatif, Kualitatif dan $R \& D$. Bandung: PT Alfabet.

Suryana.1990. Analisis Usahatani Dan Nilai Tambah. Yogyakarta : Grafindo. 